\title{
LOS MODELOS DE ANÁLISIS FENOMENOLÓGICO DEL JOVEN HEIDEGGER. UNA DISCUSIÓN SOBRE EL LUGAR POLÍTICO DE LA FILOSOFÍA.
}

\author{
FRANCISCO DE LARA \\ Pontificia Universidad Católica de Chile*
}

\begin{abstract}
RESUMEN: El presente trabajo pretende ser un aporte a la discusión actual sobre las implicaciones políticas de la filosofía de Heidegger. A tal efecto, se remonta a la filosofía del joven Heidegger y presenta los dos grandes modelos de análisis fenomenológico que éste pone en marcha en sus primeros cursos de Friburgo. Gracias a ello se vuelve posible hacer explícitas sus convicciones acerca del objeto y el sentido de la filosofía, así como sobre la relación de ésta con lo que el mismo Heidegger considera lo originariamente histórico. Por este camino se hacen visibles ciertos gestos políticos de signo jerárquico y elitista operando ya desde el inicio de su pensamiento.
\end{abstract}

PALABRAS CLAVE: Heidegger; motivo-tendencia; direcciones de sentido; historicidad; negación; política.

\section{The models of phenomenologigal analysis by the young Heidegger. A discussion about the political place of philosophy}

ABSTRACT: This paper is intended to be a contribution to the current debate about the political implications of Heidegger's philosophy. For this purpose, I focus on the philosophy of the young Heidegger in order to explore the two fundamental models of phenomenological analysis that he uses in his first lecture courses in Freiburg. This analysis allows me to make explicit Heidegger's convictions concerning the object and the sense of philosophy, as well as his connection with what Heidegger considers the originally historical. Due to this, it becomes possible to recognize the presence of hierarchical and elitist political signs that already were working from the beginning of his thought.

KEY WORDS: Heidegger; motive-tendency; sense directions; historicity; negation; politics.

\section{INTRODUCCIÓN}

Este trabajo pretende contribuir a reflexionar sobre el lugar político de la filosofía en un momento en el que el pensador del que aquí trataremos, Martin Heidegger, vuelve a excitar un apasionado debate al respecto ${ }^{1}$. Por

\footnotetext{
* El presente trabajo ha sido realizado en el marco del Proyecto Fondecyt Regular número 1160072 de Conicyt, Chile.

1 Me refiero, obviamente, al debate ocasionado por la publicación de los Cuadernos negros (cf. GA 94-97) y del libro de TrawnY (2014), al que reaccionaron otros muchos, entre los que destaco los de Cohen-Halimi y Cohen (2015), Noll (2015), Heinz y Kellerer (2016), Mehring (2016 y 2018), Homolka y Heidegger (2016), y Gander y Striet (2016). Permítaseme citar la caracterización que hice del asunto en otro trabajo: "Cíclicamente resurge una discusión sobre la posición política de Heidegger. Primero, y ya desde 1933, se debatió su nazismo; ahora, probado éste, se busca esclarecer definitivamente su antisemitismo de la mano de una novedad editorial como los Cuadernos negros. Toda esta controversia, el llamado
} 
desgracia, este tipo de debates - tan necesarios para la filosofía en un tiempo de ultraespecialización académica- degenera fácilmente en la confrontación ciega entre los extremos de la condena oportunista y la apología o el silencio interesado. Para que el debate alcanzara cierta altura de miras, sería necesario apuntar a la pregunta de fondo que, me parece, cabe recuperar y poner en primer plano ahora. Me refiero a la cuestión por el lugar y la responsabilidad política y pública de la filosofía. Pensarla implica desplazarse desde la cómoda posición de estudioso pretendidamente apolítico, pero sin que tal desplazamiento implique desdeñar o considerar superfluos los resultados que sólo un trabajo serio con el autor en cuestión puede arrojar. Es preciso evitar todo diletantismo y proceder con la meticulosidad del más escrupuloso especialista, pero manteniendo en el horizonte y haciendo explícitas desde el principio las preguntas directrices que motivan y vuelven necesario un trabajo riguroso de análisis con los interlocutores escogidos, en este caso Heidegger.

Múltiples son las vías que dicho análisis podría tomar, y múltiples también las que permiten tratar la cuestión de fondo sobre las posiciones políticas implicadas en las diversas formas de hacer filosofía. Por mi parte, considero que un camino especialmente fructífero pasa por examinar el modo como las principales corrientes de la filosofía contemporánea han entendido la historicidad, el acontecimiento, el cambio con incidencia en la vida común. En los distintas formas de pensar el acontecimiento y la historicidad me parece posible reconocer gestos políticos en cuanto respuestas a la siguiente pregunta: ¿desde dónde y cómo se originan los cambios históricos? La respuesta que una filosofía ofrece a esa pregunta muestra su posición acerca de cuáles son las instancias políticamente relevantes; y permite apreciar, a un tiempo, qué papel se le asigna a la filosofía misma en la vida pública. De ahí que me parezca necesario explicitar el modo como las más importantes corrientes del pensamiento contemporáneo entienden el origen y el carácter de lo histórico, a fin de acabar debatiendo con ellas sobre los supuestos y gestos políticos que tal comprensión implica.

Para lograrlo, sin embargo, no basta con rastrear y analizar los pasajes donde tal o cual pensador o pensadora tematizan lo histórico o definen la actitud que la filosofía debería adoptar ante lo público. A mí entender resulta preciso

\footnotetext{
"caso Heidegger", ha vivido ya diversas etapas, y hay quien divide las posturas al respecto en al menos ocho (Тнӧма, 2003, p. 159), lo que da una idea de la complejidad del debate. Lo relevante de esta discusión no consiste, sin embargo, en decidir si la persona Heidegger, o el profesor universitario Heidegger defendieron o compartieron tal o cual ideología. La pregunta de fondo es ante todo si el filósofo Heidegger lo hizo, es decir, si su filosofía misma es o al menos contiene rasgos de lo podría denostarse y repudiarse como contrario a todo pensamiento propiamente dicho. Se pretende decidir, por ende, si su filosofía es derechamente ideología - y además ideología nazi-o al menos contiene suficientes gérmenes de ésta como para que sus fortalezas, sus logros y su influencia filosófica se vean decisivamente opacadas, hasta el punto de resultar ya imposible defender la seriedad de Heidegger como pensador" (De LaRa, 2014).
} 
también, y además como condición previa, analizar esas filosofías y entenderlas tanto en sus pretensiones e intuiciones más fundamentales como sobre todo en su forma de proceder. En efecto, únicamente la dilucidación de los elementos metódicos centrales de una filosofía permite apreciar dichas intuiciones a plena luz. Sólo mediante la explicitación de los elementos que juegan un papel fundamental en la forma de proceder de una filosofía podemos constatar qué pretende ésta propiamente, qué busca, cómo enfoca los fenómenos, a qué le da importancia y qué deja de lado. En los modos de proceder encontramos casi siempre decisiones sobre el asunto del que debe ocuparse la filosofía y sobre la manera como tal asunto debe ser tratado. Dicho lapidariamente, en el método se esconden las tesis más recónditas de una filosofía.

Por este motivo, las páginas que siguen se centrarán ante todo en el análisis del modo de proceder de Heidegger. Dicho análisis, además, estará dirigido a una etapa de su pensamiento poco tratada para nuestra temática política, por ser muy anterior al periodo nacionalsocialista. En concreto, intentaré mostrar cómo hace filosofía el Heidegger de los primeros cursos friburgueses (19191923) para ver entonces qué tesis con relevancia política está asumiendo. En concreto, empezaré detallando los modelos de análisis fenomenológico de los que hace uso Heidegger a la hora de tematizar al Dasein en dichos cursos, esto es, la forma como examina el fenómeno de la vida humana. Veremos que son fundamentalmente dos los patrones de análisis fenomenológico que le permiten a Heidegger obtener lo que él considera un conocimiento genético de la vida, esto es, un conocimiento de la vida desde el núcleo en el que ésta se originaría. Por esa vía, quedará claro que esta forma de hacer filosofía constituye, a un tiempo, un intento de pensar la historicidad del Dasein, que Heidegger considera la historicidad originaria. Además, se apreciará el rol fundamental que la negación juega en este modo de enfocar el fenómeno histórico por antonomasia. Con estos elementos en la mano - los modelos de análisis fenomenológico, el rol de la negación y la pretensión de estar pensando la historicidad originaria- estaremos en condiciones de hacer visibles los aspectos de importancia para nuestra pregunta de fondo sobre el gesto político de esta filosofía. Ello nos permitirá iniciar una discusión fundada que aporte, quizá, algún elemento al actual debate.

\section{Primer modelo de anÁlisis fenomenológico: Motivo-tendencia.}

Al igual que el pensamiento de muchas de las principales corrientes filosóficas de su época, la filosofía temprana de Heidegger está movida por la pregunta acerca de «la vida» o el vivir (das Leben). Tal como recuerda R. Rodríguez, «hay que tener en cuenta el motivo «vitalista» que conduce el planteamiento de Heidegger: se trata (...) de mostrar la estructura fundamental del fenómeno 
originario (Urphänomen) de la vida" (Rodríguez 1997, pp. 73-74)². ¿En qué consiste vivir, pues? ¿Hay algo así como una estructura desde la que la vida humana se manifieste y a partir de la cual se vuelva comprensible?

Heidegger responde a esta pregunta afirmativamente y, en sus primeros cursos de Friburgo, ensaya ante todo dos modelos para dilucidar dicha estructura. El primero de estos modelos considera que la vida se estructura a partir de la articulación de motivos y tendencias. Este es el modelo que domina todavía en el denominado Kriegsnotsemester de 1919, mientras que en el curso de 1919/20, titulado Problemas Fundamentales de la Fenomenología, se introduce ya el segundo modelo. Este afirma que la vida es una «totalidad de sentido" (Sinnganzheit) articulada en distintas "direcciones de sentido»: sentido de contenido, de relación y de ejecución. Introducir este último modo de análisis fenomenológico, sin embargo, no obliga a Heidegger a desplazar o rechazar el anterior, sino que, como veremos, le permite mantenerlo despojado de los elementos que podrían ser más problemáticos del mismo, y apuntar más decididamente a lo que para él es fundamental en la comprensión de todo fenómeno humano.

Con estos dos modelos se pretende dar respuesta a la siguiente pregunta: ¿qué le otorga su particular fisonomía a la vida tal y como la experimentamos? $\mathrm{O}$, dicho de otra manera, ¿de qué depende estructuralmente el aparecer de los fenómenos? La pregunta adquiere en los primeros cursos de Heidegger la formulación diltheyana sobre las categorías que hacen comprensible a la vida humana para sí misma, que le permiten a dicha vida comprenderse sin caer en esquemas propios de disciplinas particulares. La primera respuesta de Heidegger al respecto, que encontramos explícitamente esbozada al final del denominado Kriegsnotsemester (GA 56/57) ${ }^{3}$, dirá que el vivir tiene la forma de un dirigirse a algo con ciertas pretensiones (tendencia) que se derivan de algún motivo (motivación).

Este último y fundamental término, «motivación», es usado por Heidegger en varios contextos y adquiere en ellos algunos matices de no menor importancia ${ }^{4}$.

2 Sobre la relación (crítica) de Heidegger con el vitalismo y en especial con Dilthey pueden consultarse, entre otros, BAмвасн (1995), Кiм (2001), Sснмidt (2005) у Le Moli (2005).

3 Las obras de Heidegger serán citadas según el criterio internacional, esto es, indicando las siglas GA (Gesamtausgabe) seguidas del número de volumen y de página.

4 El vocabulario de la Motivation domina este primer curso friburgués desde el inicio, cuando Heidegger recurre a este concepto para determinar qué sea lo propio de la vida científica. El concepto atraviesa el curso por completo, tanto en el intento de encontrar un camino para determinar la idea de filosofía, como en la crítica del método teleológico-crítico (en la p. 48 le reconoce a Rickert haber «visto» este «importante fenómeno») o en la dilucidación de la «vivencia interrogativa» (v. GA 56/57, pp. 66-ss.). En el curso «Sobre la esencia de la universidad y del estudio académico», incluido como Apéndice I en ese mismo volumen de la Gesamtausgabe, Heidegger afirma directamente que «la forma fundamental del nexo de la vida es la motivación (die Grundform des Lebenszusammenhangs ist die Motivation)»(GA 56/57, p. 205). Aclarar con detalle los usos que Heidegger da a este término, así como al de «tendencia» y sus derivados, en este curso y los siguientes supondría un trabajo cuya extensión 
Lo fundamental al respecto es apreciar que, mediante este concepto, Heidegger pretende ante todo hacer visibles nexos «de sentido» (cf. GA 56/57, p. 66). No se trata, por ende, de establecer relaciones causales entre sucesos, sino de revelar que ciertas posibilidades de trato - y, correlativamente, de manifestaciónestán motivadas en otras y sólo se vuelven comprensibles desde ellas, esto es, al aclarar tales relaciones genéticas. Así, por ejemplo, para Heidegger la posibilidad de la vivencia teórica estaría motivada, de un modo particular, a partir de la forma de vida pre-teórica o cotidiana, y no al revés. Es evidente que la relación entre ambos modos de vivencia no es de índole causal y, según Heidegger, tampoco es de mera sucesión, sino que existiría entre ellas una relación genética. $\mathrm{Al}$ afirmar estas relaciones motivacionales se pretende mostrar que la forma de trato propia de la teoría no es primera ni independiente, sino que surge a partir de otras formas de trato y como una determinada modificación de las mismas. Entender la actitud teórica desde su génesis de sentido implicaría, por ende, mostrar el tipo de movimiento que se genera en la vida fáctica en dirección a una posibilidad de vivenciar tan peculiar como esa. Esto permite constatar una serie de conexiones motivacionales en el modo como algo acaba apareciendo, tal y como Heidegger intenta ilustrar, por ejemplo, al explicitar los pasos que van desde la vivencia cotidiana al «tomar en conocimiento» (Kenntnisnahme) y de éste al conocimiento objetivo de cosas (cf. GA 58, §§ 25 y 26), o bien los pasos de la «des-vivificación» teórica en el ejemplo de la vivencia de la cátedra (GA 56/57, p. 113). Según esto, entonces, resultaría posible definir las «series motivacionales» que dan lugar a un cierto modo de aparición. También sería posible, de esta forma, descubrir que hay determinaciones y correlativos modos de trato que no están ligados a series de pasos, como por ejemplo una determinación formal del tipo «algo en general». Esto permite mostrar que tal determinación posee un carácter distinto, y que por ende está motivada de una manera radicalmente distinta que una determinación teórica pero material —como «superficie de color», por ejemplo- (cf. GA 56/57, pp. 113-ss., GA 58, pp. 107, 216-217 y GA 60 , pp. 55-ss.).

Como puede apreciarse, Heidegger estaría enunciando una tesis fundamental al considerar los modos de experienciar en términos de motivación, a saber: que una vivencia concreta puede tener detrás de sí «condiciones» previas según su sentido, es decir, que sólo se llega a vivenciar algo de esa manera sobre la base de una forma distinta de experienciar con la que la segunda guarda cierta relación de dependencia. El término «motivación» apunta, entonces, a mostrar las condiciones de posibilidad que se encuentran en la base de ciertos modos de trato. De ahí que, en el caso de la vivencia teórica dirigida a contenidos, sea

impediría volver a las preguntas de índole política que ponen en marcha este escrito. En lo que sigue, no obstante, intentaré dar cuenta de los aspectos fundamentales implicados. Algunas luces al respecto pueden encontrarse en KISIEL (1997), pp. 27-29 y 33; KIM (2001), pp. 59-60, 80-82, 95-96; Lepadatu (2009), pp. 56-64 y RadinKović (2012), pp. 253-ss. En todo caso, a mi entender sigue faltado un estudio sistemático que aclare detalladamente este par de conceptos y su decisivo rol en la filosofía del joven Heidegger. 
posible mostrar incluso que en este modo de vivenciar tiene lugar una serie de pasos o niveles, un concatenamiento en el que hay motivos más originarios que otros, es decir, anteriores en la cadena de motivaciones. Para Heidegger la tarea fundamental de la dilucidación fenomenológica consistirá en encontrar los «motivos fundamentales», las primeras posibilidades de trato que ponen en marcha el resto a partir de procesos con sus propias motivaciones (que, si bien pueden resultar incluso contrarias a la dirección general de la motivación anterior, en todo caso dependen de ella según su sentido; son por así decir deudoras de ella). En el caso de la vivencia teórica dirigida a contenidos objetivos - la vivencia de "algo cósico-objetual»- Heidegger encuentra su origen en la vivencia del mundo circundante, de «algo mundano». En cambio, la vivencia teórica formal, que considera algo simplemente como «algo» y sin atender a su particularidad, no es una posibilidad de trato que se motive en modo alguno en la vivencia cotidiana del mundo. La vivencia formal de algo no tiene lugar a partir de un proceso de generalización cosificadora motivado en última instancia en la vivencia cotidiana, por más que transformador de ésta. Este último proceso de transformación teórica pueda ser descrito en sus pasos (motivos) fundamentales sin que se encuentre elemento alguno que apunte a la formalización ${ }^{5}$. No es posible entender cómo se llega al algo formal siguiendo ese proceso generalizador, por lo que es preciso buscar otro «origen» motivacional en este caso, es decir, dar con formas de experiencia pre-teóricas que no estén dirigidas a ningún contenido aún, que rompan con la primacía del contenido que es propia de la experiencia habitual. De ahí que Heidegger acabe considerando la experiencia de "algo pre-mundano» como génesis de sentido de la formalización (cf. GA 56/57, p. 115).

En general, como decimos, la pretensión de Heidegger en sus primeros cursos consiste en establecer este tipo de relaciones genéticas. Es significativo, sin embargo, que lo haga en términos de «motivación». Con ello indica que entiende las vivencias como posibilidades de trato movidas por algo no solamente en el sentido recién comentado - en cuanto dependientes de otras formas previas de trato-, sino también y principalmente como un dejarse llevar por un cierto movimiento, entregarse o ponerse en una posibilidad que tiene la forma de un impulso, de una movilidad. En seguida entraremos en eso. Baste ahora con indicar, a modo de introducción, que entender la vida en términos de dinámicas o movilidades ${ }^{6}$ le permite a Heidegger conectar el concepto de motivación con el de tendencia. En efecto, el movimiento en que la motivación consiste hace que la vida se dirija en una cierta dirección y con determinadas pretensiones, siendo esto justamente lo que nuestro pensador

5 La razón de ello, como se ha indicado ya, es que el proceso de «desvivificación» está centrado siempre en los contenidos, dirigido a ellos en su particularidad. De ahí que Heidegger considere posible establecer una relación de motivación entre el "algo mundano» y el «algo cósico-objetual», aunque la dirección y el modo de experimientar algo sean muy diversos en cada uno de esos dos casos.

6 V. al respecto Martínez Matías (2005). 
indica al hablar de tendencias. Así pues, y de forma sintética, podría decirse que con el concepto de «motivación» Heidegger pretende responder a la pregunta sobre el desde dónde y el porqué de una determinada manera de vivenciar, mientras con el de «tendencia» responde sobre el hacia qué, cómo y para qué, como pasamos ahora a mostrar.

Resulta posible expresar formalmente esta estructura fundamental de la vida, la estructura de motivación-tendencia, como sigue: la vida, movida por algo, se dirigiría siempre hacia algo con miras a algo, es decir, con ciertas pretensiones y en un cierto respecto. A fin de que se comprenda mejor lo así expresado, es preciso sin embargo aclarar a qué se dirige la vida y de qué manera se relaciona con ello. En su forma de realización más habitual, la propia de la experiencia cotidiana, la vida se dirige a algún útil, siendo esto lo que por lo general centra su atención, y lo hace con miras a emprender algo con ello. Aquello a lo que se dirige habitualmente no presenta, según Heidegger, el carácter de objeto que es correlato de una consideración teórica, sino que aparece en el contexto de los asuntos que nos ocupan en ese momento. Lo que aparece intencionalmente, aquello a lo que nos dirigimos, es algo relevante (o no) dentro de un contexto de ocupación: está intendido siempre desde una cierta posibilidad de la ocupación, en cuanto útil o no, favorable o no, propicio o no, para eso en lo que andamos. La dirección de la vida cotidiana, su tendencia, tiene para Heidegger la forma de un hacer uso de algo para algo. El modo como algo aparece depende por tanto de en qué andemos, qué pretendamos con ello, esto es, de la posibilidad a la que nos estemos entregando. Lo que en primera instancia monopoliza nuestra atención, aquello a lo que nos dirigimos, aparece como lo hace porque nos dirigimos a ello desde alguna posibilidad a la que nos hemos entregado.

Esta forma de aparecer depende, por tanto, de lo que nos mueve a hacer nuestras justamente esas posibilidades, de lo que nos motiva. La tendencia, por ende, debe ser entendida desde y en conjunción con la motivación. Por su parte, estas motivaciones pueden ser vistas en cadena, como dijimos ya: es posible remitirlas a algo así como motivos fundamentales. Dichos motivos fundamentales tienen también la forma de posibilidades, si bien ahora no de las posibilidades concretas que se pueden emprender en una situación, sino de las posibilidades de vida que mueven a ponerse justamente en tales o cuales situaciones. Así, por ejemplo, que un libro de Heidegger u otro pensador aparezca para nosotros en cuanto algo donde encontraremos alguna concepción de importancia para entender qué es la filosofía, que esta sea por tanto la tendencia de nuestra vida, depende a su vez de que nos dejemos mover, de que hagamos propia la posibilidad de dedicarnos a la filosofía y queramos progresar en esta decisión. Pero perfectamente podríamos tomarlo como un objeto de curiosidad, para saber en alguna medida qué dice, o bien de estudio académico, para lograr dominar y exponer el supuesto contenido doctrinal del libro, etc. Aquello a lo que nos dirigimos —el «contenido» del libro- aparecerá de uno u otro modo dependiendo de todo ello. Así, que nos dirijamos a tal o cual ente y que lo hagamos con miras a tal o cual fin depende finalmente de las posibilidades de vida que nos mueven en cada caso. La vida puede 
ser dilucidada entonces desde este punto de vista, explicitando qué mueve a dirigirse a algo con ciertas pretensiones y cierta direccionalidad, esto es, de qué manera se articulan motivos y tendencias ${ }^{7}$.

Es fundamental señalar que Heidegger entiende estas motivaciones ante todo como movimientos de la vida en dos direcciones generales contrapuestas. Según él, la vida encuentra motivos para hacer problema de sí misma y buscar claridad sobre sí o bien, en la dirección opuesta, para huir de esa preocupación y mantenerse en una cierta indiferencia respecto de sí. Este elemento básico —la relación de mayor o menor responsabilidad que el existente concreto establece con su propio vivir - es de suma importancia en la comprensión heideggeriana de la vida humana y su estructura. Al final, lo que permite comprender la vida será justamente ver de qué manera el existente humano se hace cargo de este aspecto, qué tipo de movilidades y tendencias pone en marcha esta inquietud y problematicidad del existir. En efecto, para Heidegger es ante todo esa misma in-quietud la que mueve en última instancia, el proto-motivo que impulsa a moverse en las dos direcciones contrapuestas ya indicadas: la apropiación o la huida de sí. De este modo, Heidegger consideraría haber dado con los elementos primarios para la dilucidación de la vida, aquellos que ponen en marcha y atraviesan todos las otras formas de experiencia vital, incluyendo el modo de vida cotidiano. El proto-motivo sería la inquietud ante el propio tener que ser y hacerse cargo de ese mismo estar siendo, lo que daría lugar a las dos grandes tendencias contrapuestas recién mencionadas, la apropiadora y la huidiza. Estas se concretarían entonces en los más diversos modos de realizar la vida, los cuales a su vez consistirían justamente en la articulación de ciertos motivos y tendencias. De esta manera, Heidegger dispondría de un primer instrumentarlo metódico-formal que le permitiría interpretar cualquier manifestación de la vida y cualquier vivencia.

\section{El MOdELO DE LAS DiRECCIONES DE SENTIDO COMO ORGANON FENOMENOLÓGICO}

Sin embargo, un modelo como este - en el que se consideran las experiencias concretas a partir de grandes posibilidades de vida- puede derivar fácilmente en intentos de tipificación de dicha vida, dando lugar a una estructuración meramente formal de la existencia a partir de tipos humanos como el económico, estético, teórico, político, religioso, etc. En efecto, tanto en Dilthey —en su idea de tipos de cosmovisiones, expuesta en la Teoría de las cosmovisiones de 1911 (Dilthey 2006) — como sobre todo en algunos de sus seguidores, especialmente

\footnotetext{
7 Por mor de la brevedad, dejaré aquí sin exponer la forma típica como motivos y tendencias se articulan en la vida cotidiana, esto es, lo que Heidegger denomina la "autosuficiencia de la vida» (v. al respecto GA 58, pp. 30-31 y 41-42).
} 
Eduard Spranger ${ }^{8}$, se fue imponiendo este camino más idealista-formalista, en el que el existente concreto se ve reducido a un caso individual que encarna un ideal o tipo general ${ }^{9}$.

Frente a ello, el segundo modelo de comprensión de la vida que Heidegger pone en juego ya al final de su curso de 1919/20 le permite mantener y apuntalar lo esencial de su postura, y a la vez conservar y hacer uso de los conceptos de motivo y tendencia en el sentido preciso que él les otorga, más allá de toda tipificación y en cuanto índices de las movilidades fundamentales de la existencia. Por esta vía, el modelo de las direcciones de sentido se convierte en paradigma de interpretación de la vida humana. Gracias a los conceptos de sentido de contenido, relación y ejecución ${ }^{10}$, Heidegger evita entender el fondo del que depende la manifestación, el elemento que configura finalmente la experiencia vital fáctica, como un movimiento que remite a tipos ideales o formas impersonales de vida. Al afirmar la centralidad del sentido de ejecución (Vollzugssinn), Heidegger logrará poner el acento en el «mundo del sí mismo» (Selbstwelt) —en la relación de mayor o menor responsabilidad que el existente concreto guarda con su propia vida- como origen desde el que se hace comprensible dicha vida en todas sus posibilidades y manifestaciones.

Este modelo de las direcciones de sentido opera ya plenamente en el curso de 1920 titulado Fenomenología de la intuición y la expresión. En él se mantiene la pregunta directriz de estos primeros cursos friburgueses acerca del carácter de la filosofía y se vuelve a intentar responder dicha pregunta buscando justamente un motivo que haga surgir la filosofía del ámbito en el que se encuentra por lo general y casi siempre la vida: la experiencia fáctica que es propia de la cotidianidad. El motivo que se empieza a identificar y desarrollar aquí —lo que movería a que el filosofar abriera una brecha en las formas habituales de relacionarse con algo - no es otro que lo histórico, y concretamente la inquietud frente a lo histórico. Heidegger considera que, bajo el problema de la vida al que se dedica buena parte de las filosofías de su época, se encuentra finalmente

8 V. ante todo su Formas de vida (1921). Heidegger discute el modo de consideración de Spranger —quien, según él, habría «aguado sistemáticamente» a Dilthey (GA 63, p. 14) — y sus contemporáneos en GA 63, pp. 42-ss. También se hace cargo en estos cursos de concepciones como las de Weber y Jaspers en las que la tipificación juega un papel importante (v., respectivamente, GA 58, pp. 190-196 y GA 9, p. 39).

9 Este impulso a la tipificación es especialmente apreciable en la manera como Oswald Spengler trata los fenómenos históricos, esto es, humanos. Aunque este punto no ha sido demasiado trabajado aún entre los especialistas (excepción hecha de BARASH (2003), pp. 113ss.), es de señalar que Heidegger se ocupa de Spengler a lo largo de sus primeros cursos friburgueses y que la discusión con él resulta de la mayor importancia para entender su concepción de la historicidad.

10 Una exposición detallada de estas direcciones de sentido puede encontrarse en el primer capítulo de De LaRA (2008), pp. 31-ss. V. también la entrada «Directions de sens (Sinnrichtungen)» en el Abécédarie de Heidegger editado por A. BEAulieu (2008) y las entradas «content sense», «relational sense», «actualization sense» $\mathrm{y}$ «temporalizing sense» en ScHALOw y DenKer (2010), así como las exposiciones de Greisch (2000), pp. 65-s.; RodríGuez (1997), pp. 53-56; Volpi (1988), p. 207; GANDER (2001), pp. 283-s.; LAZZARI (2002), p. 123 y MARTínez (2005). 
esta inquietud; ella sería el elemento que mueve y con el que se confrontan en última instancia no sólo dichas filosofías, sino la filosofía en general. Aquello desde lo cual pero también contra lo cual surgiría la filosofía sería nada menos que lo histórico, esto es, la contingencia, la finitud del Dasein, su tener que habérselas consigo mismo en un contexto de significación ya heredado ${ }^{11}$.

Al ser la historia lo que parece subyacer a las problemáticas filosóficas de su tiempo, y al manifestarse en ello algo fundamental para entender la filosofía en general desde su motivo originario, Heidegger emprenderá en este curso de 1920 la discusión de dos posturas de importancia -representadas por Natorp y Dilthey - en vistas a considerar el modo como éstas entienden y se relacionan filosóficamente con lo histórico. A fin de establecer una base adecuada para dicha discusión, Heidegger empieza distinguiendo seis sentidos como puede ser vivido lo histórico y los examina justamente desde el modelo de las direcciones de sentido. Se tratará de analizar seis modos de aparecer -y, correlativamente, de vivir- la historia a partir de los sentidos de contenido, relación y ejecución implícitos en cada una de esas experiencias de lo histórico. Explicitar estas experiencias según el modo como se articulan estos sentidos es para Heidegger lo que permitirá comprenderlas, dado que con esa articulación se lograría mostrar su «lógos», como dirá en el curso siguiente ${ }^{12}$.

Tenemos entonces, según esto, que en toda experiencia aparece algo y que su modo de aparecer (sentido de contenido) es correlato de un modo de relacionarse con ello (sentido de relación) y, en especial, de la manera como se vive esa relación (sentido de ejecución). La vida tendría siempre esta estructura, por más que sea característico de la experiencia habitual y cotidiana el estar centrada en aquello con lo que nos ocupamos, en lo que aparece, y dejar en segundo plano los demás aspectos. Esta centralidad del «contenido» lleva a Heidegger a afirmar que "lo propio de la experiencia vital fáctica es que el "cómo yo me sitúe respecto a las cosas", el modo de experienciar, no sea [ello mismo] co-experienciado» (GA 60, p.12). El procedimiento metódico que permite comprender los fenómenos vitales consistirá, por tanto, en quebrar esta centralidad del contenido e interrogar por la estructura plena que lleva a que algo aparezca como lo hace.

Así pues, aplicado al caso que le interesa a Heidegger, el modo como comparece lo histórico (su sentido de contenido) es correlato de un cierto modo de acceder y relacionarse, de habérselas con ello, de vivirlo y tratarlo (su sentido de relación). En el mencionado curso, Heidegger introduce y analiza seis expresiones como base para introducir en situaciones de experiencia de lo histórico que indican

11 En el curso inmediatamente siguiente, la Introducción a la Fenomenología de la Religión, Heidegger pretende esbozar tres grandes formas de respuesta a esta inquietud, características de la filosofía en general y también de la filosofía de su época. Cf. GA 60, pp. 39-ss. Al respecto, puede verse De LARA (2014), pp. 66-67.

12 De ahí que para este Heidegger la «fenomenología» deba consistir en la «explicación

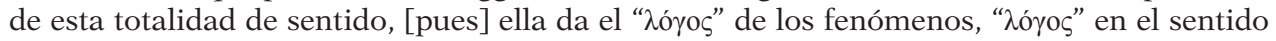
de "verbum internum"»(GA 60, p. 63). 
otros tantos modos de relacionarse con ello (V. GA 59, pp. 43-ss.). Según esto, el modo concreto como algo comparece estaría ligado a una manera de acceso, a una forma de relación, y por ende a la puesta en marcha de ciertas posibilidades de trato. El «contenido» no es algo que esté meramente ahí para una captación neutra por parte de un sujeto él mismo neutro. Lo histórico está visto en cada caso en un cierto respecto y una cierta dirección que es correlativa a una forma de relación viva y concreta que alguien, también concreto, pone en marcha. Al subrayar esto, Heidegger inicia la operación metódica de «des-enajenar»al Dasein (cf. GA 63, p. 15), pues lo que aparece deja de hacerlo como algo ajeno y que meramente está ahí, que se recibiría como dado. Nuestro existir no consiste en un pasivo desplazarnos de un contenido dado a otro, sino que en todo momento nos estamos relacionando de alguna manera y estamos adoptando una forma de trato con lo que es el caso para nosotros.

Este aspecto de la relación (Bezug) le va quitando la centralidad al sentido de contenido y, a una con ello, al mundo circundante (Umwelt) con el que se ocupa el Dasein, para apuntar al mundo del sí mismo (Selbstwelt) como ámbito desde el que se origina el modo específico como algo comparece. Así, por ejemplo, que la historia aparezca como una disciplina científica - un conjunto de procedimientos de investigación- o bien como el ámbito de los hechos pasados en su totalidad es correlato de una determinada relación con lo histórico, muy distinta de la que se pone en marcha cuando esto histórico aparece como algo en lo que estamos bajo la forma de tradiciones, cuando se lo ve como algo que puede orientarnos en la vida o, más aún, cuando se considera la historia de alguien, esto es, su vida personal (cf. GA 59, pp. 43-ss.).

Como qué aparece lo histórico en cada uno de estos casos es algo que depende y va unido a distintas formas de acceso y trato, que no son finalmente sino otras tantas posibilidades de efectuar nuestro existir. Este último aspecto es el que pone de relieve la tercera dirección de sentido, el sentido de ejecución (Vollzugssinn). Mediante él se deja en claro que todas esas formas de relación no son meras estructuras neutras o posibilidades formales a disposición para un sujeto también formal y neutro, sino modos como cada Dasein históricoconcreto lleva a cabo su vida, posibilidades en las que se pone y desde las que responde de alguna manera a la necesidad de hacer algo consigo mismo, de preocuparse por su propia vida. El sentido de relación no tiene, por ende, la última palabra sobre una experiencia y sobre lo que en ella comparece, sino que es preciso examinar también de qué manera dicha relación apunta (o no) al propio estar siendo, al mundo del sí-mismo, y en qué medida el existente tiene en claro que de lo que se trata en todo caso es de dicho estar siendo. Así, por ejemplo, si la historia comparece a la manera de un campo temático, esto será correlato de una forma de relación teórica que constata y ordena dicho campo como algo en el fondo dado y ajeno, algo en lo que a lo sumo «estamos» en sentido objetivo. A la posibilidad y el sentido propio de esta forma de relación le corresponde que su ejecución no apunte al propio estar siendo; antes al contrario, le corresponde que la propia existencia sea apartada expresamente como requisito para poder acceder a lo histórico de esta manera. Hay, pues, 
formas de relación — de acceso y trato- que exigen una implicación personal directa y que obligan al Dasein a enfrentar de alguna forma ese problema que él es para sí mismo. Otras formas de relación, en cambio, permiten e incluso exigen dejar ese problema de lado y mantenerse en una cierta pasividad, receptividad y «enajenación» en ese sentido. De ahí que los criterios para juzgar las distintas formas de ejecución o efectuación (Vollzug) sean para Heidegger justamente este: a) que se trate de la efectuación de una relación que, incluso si se dirige a otra cosa, apunte también genuinamente al mundo del sí-mismo del Dasein concreto que la efectúa (es decir, que deje claro que en última instancia se trata siempre de su existir); b) que sea precisa una renovación de esta efectuación por parte de ese Dasein concreto (es decir, que no se convierta en una mera actitud y una forma obvia y ya ganada de acceso); y c) que esa exigencia de renovar la efectuación y esa renovación misma sean parte de la existencia de ese Dasein (esto es, que no se trate de una mera actividad profesional o rutinaria, sino que su propio vivir esté en juego en todo ello) ${ }^{13}$.

El análisis de las direcciones de sentido en su particular articulación se convierte de esta manera en organon fenomenológico por antonomasia. Desde este instrumentario metódico emprende Heidegger el examen no sólo de cualquier experiencia de la vida, sino también de todo discurso, pues éste tan solo expresaría formas de experienciar(se) del Dasein. Desde aquí se emprende también, por ende, la crítica de otras posturas filosóficas. Se tratará de buscar en su discurso aspectos que permitan vislumbrar el sentido de contenido, relación y ejecución que es propio de su trato con los fenómenos, y particularmente con este protofenómeno que es la historicidad del Dasein. Sobre la base de este análisis se le hace posible a Heidegger manifestar cómo se responde al motivo fundamental de la inquietud de la existencia ante su propio tener que ser, el tipo de tendencias que se ponen en marcha como respuesta a ella. Como es bien sabido, este procedimiento de mostración de las experiencias fundamentales, los motivos y las tendencias directrices de una experiencia a partir del análisis de la misma según las direcciones de sentido es denominado por Heidegger destrucción ${ }^{14}$.

\section{Negación E HISTORICIDAD}

En lo dicho hasta aquí, y en la centralidad de la destrucción como elemento del método fenomenológico ${ }^{15}$, se deja ver que la negación cumple un rol

13 Cf. el criterio de «dijudicación» expuesto por Heidegger en GA 59, p. 75.

14 Una exposición detallada del modo como opera en concreto la destrucción fenomenológica puede encontrarse en De Lara (2008), cap. 3.

15 Heidegger llega a afirmar incluso que dicha destrucción constituye la «expresión de la filosofía» (GA 59, p. 171). 
fundamental a la hora de manifestar la historicidad ${ }^{16}$. La pretensión toda de la filosofía consiste según hemos visto en des-enajenar al Dasein, esto es, en llevarlo a una apropiación de su modo de ser histórico, de su historicidad, a partir de la adopción de una posibilidad que se mueve en contra de las tendencias habituales de la vida. La motivación de la filosofía, lo que la pone en marcha, es la radical problematización de la propia existencia ${ }^{17}$. Este motivo activa en el Dasein que se interroga una particular tendencia a saber de sí, a autotransparentarse en lo que concierne a su carácter de ser. De este modo, en la filosofía se vuelven efectivas direcciones de atención - tendencias- que se dirigen en la dirección opuesta al estilo habitual de la vida. Este movimiento de negación tiene lugar, además, tanto a nivel pre-temático como a nivel temático. La transformación opera en el nivel pre-temático porque conduce a un cambio de la forma de vivir, interrumpe y problematiza el modo como se va decidiendo lo que hacemos y a lo que nos dedicamos. La vida se da ahora una dirección marcada, elegida, y justamente una que va en la peculiarísima dirección de aclararse a sí misma en cuanto vida. En efecto, no se trata aquí simplemente de la elección de una posibilidad marcada de existencia como podría ser la artística o la religiosa, sino de una tal que pretende poner en claro el carácter problemático de toda vida y llegar a una determinación de ésta en sus caracteres fundamentales. Así pues, este cambio en el estilo vital, esta transformación de la vida en su nivel pre-temático, conlleva en el caso de la filosofía un necesario paralelo en el nivel temático. Dado que la filosofía consiste en una tematización que busca autotransparencia radical, la elección de una posibilidad de existencia como la filosófica implica de suyo la necesidad de una toma de distancia crítica no sólo respecto de otras posibilidades de vida, sino también respecto de las formas más habituales de tematización. Se vuelve preciso, en primer lugar, delimitar y distinguir la motivación que actúa en una posibilidad de vida como la filosófica por contraste tanto con los otros modos de trato interrogativo e investigador (las ciencias) como con los otros discursos que tienen por objeto lograr una comprensión de la vida (las cosmovisiones). Además, segundo, es preciso también emprender una crítica de las filosofía del presente y de los motivos del pasado que perviven en ellas e impiden que se vuelva efectivo y directriz el verdadero motivo fundamental de la filosofía. Dicho

16 La negación ocupa, en efecto, un lugar fundamental en toda la filosofía del joven Heidegger. Esto es así porque la ya mencionada tendencia a la huida daría lugar a una serie de deformaciones que sería preciso «destruir». De ahí que «el sentido fundamental del método fenomenológico y del filosófico en general [sea] decir no, la productividad del no (sentido de la dialéctica hegeliana)» (GA 58, p. 148). Al llevar a cabo dicha negación, se opera una transformación en el sentido habitual de la existencia del Dasein, por lo que la negación no tendría para Heidegger una importancia meramente metódica, sino que también, y de la mano de ello, posibilitaría un determinado modo de ser. Por eso afirma Heidegger en el Informe Natorp que ésta posee un sentido ontológico constitutivo (cf. GA 62, p. 362).

17 V. GA 59, 171, donde Heidegger afirma que: «(...) en el motivo de la filosofía se encuentra el aseguramiento o, mejor, el volver inseguro el propio existir». V. también GA 59, p. 174. 
sumariamente, es necesario detectar en qué medida esas filosofías presentes y pasadas logran mantenerse fieles al impulso propiamente filosófico -la transparentación de la existencia como inquietud y responsabilidad-y hacer que sus tendencias se motiven únicamente desde él. La crítica de Heidegger a otras filosofías - o bien, más generalmente, al ideal teórico de conocimiento que en ellas domina- denuncia que las tendencias que ponen en marcha tales filosofías estarían motivadas de forma opuesta, esto es, que apuntarían a un aseguramiento ante el propio carácter de ser (v. GA 60, §9).

Así pues, la filosofía se mueve en dirección opuesta tanto al estilo habitual de existencia como a los discursos y modos de investigar, incluyendo el filosófico en muchas de sus formas. Heidegger considera que la necesidad de ir en contra de la tendencia al aseguramiento de la vida es estructural en filosofía justamente porque esa misma tendencia lo es en grado sumo. La huida de sí no es un rasgo psicológico, propio de algunos individuos o especialmente marcado en algunas épocas, sino un rasgo tan constitutivo del Dasein como la tendencia a la apropiación de sí, pero mucho más habitual y dominante. Aquí encontramos esbozadas una vez más, en definitiva, las dos grandes direcciones de la movilidad de la vida, las dos posibilidades formales que, según Heidegger, la caracterizan en cuanto respuestas al proto-motivo de la inquietud existencial: apropiación o huida, responsabilidad o delegación. La tensión entre ambas tendencias explica la necesidad estructural de crítica y negación, el lugar eminentísimo que éstas ocupan en la investigación filosófica y en sus pretensiones de volver al Dasein despierto, preocupado de sí.

Por este camino de interrogación crítica del Dasein acerca de su modo de ser se vuelve posible, como hemos apuntado ya, hacer tema de dicho Dasein en su carácter histórico. La historicidad, decíamos, es aquello que inquieta y de lo que huye tanto la vida pre-temática como las investigaciones y tematizaciones sobre el hombre. Esto es así porque, bajo el título de historia e historicidad, nos enfrentamos, según Heidegger, con el fenómeno de la vida humana. El concepto señalaría el tener que ser del Dasein en posibilidades que en el fondo son heredadas y que, además, son vividas siempre desde las dos grandes posibilidades formales ya indicadas: la posibilidad de apropiarse de ellas o bien la de estar en ellas sin más. Este sería para Heidegger el sentido más originario de la palabra historia; lo mentado en última instancia al hablar de lo histórico no sería sino el modo de ser del Dasein en cuanto esa problemática apertura a posibilidades heredadas y necesitadas de apropiación.

Así pues, Heidegger considera la historia en última instancia como repertorio de posibilidades ejecutadas en primera persona, por diversos individuos, de modo tal que llegan a volverse relevantes en la vida común y a ser parte de nuestra tradición. Tales posibilidades llegarían a nosotros ya anquilosadas, por lo que se volvería necesario destruirlas a fin de redescubrirlas como auténticas posibilidades de vida que nos pueden incumbir, que podemos elegir. Esta forma de ver la historia pretende estar descubriendo lo originariamente histórico, esto es, el fondo que origina lo que después acaba teniendo una figura pública, ya nivelada y de fácil acceso. Así pues, parecería que para Heidegger lo decisivo 
en la historia serían esas posibilidades encarnadas y ejecutadas por individuos ejemplares, ellos mismos históricos en el sentido de epocales. Los cambios con incidencia en la vida común - en el modo de vivir, relacionarse y comprenderse los seres humanos- serían generados por un reducido grupo de individuos, en su ejecución especialmente radical y coherente de decisiones vitales. Movidos por la inquietud de la existencia, sus vidas fueron grandes respuestas que le dieron su fisonomía al mundo tal y como lo conocemos, pues trazaron los raíles por los que se desplaza hoy, impropiamente, la existencia pública.

En este modo de consideración de lo histórico se hace patente, entonces, un cierto desprecio por la esfera pública, en la medida en que se la comprende como secundaria y fundada. No sería en el ámbito de las luchas políticas de comunidades o grupos, ni tampoco en condiciones de índole material donde habría que buscar el origen de las transformaciones históricamente relevantes. La verdadera transformación — lo que hace «época» y no «ruido» (cf. GA 56/57, 5) - tendría para este Heidegger un carácter privado, personal; y sería, ante todo, de índole espiritual-vital. La transformación de la propia vida mediante la asunción de posibilidades expresadas en ideas parece ser, por tanto, el modelo desde el que Heidegger piensa toda transformación histórica radical ${ }^{18}$.

\section{UNA CONTRIBUCIÓN AL DEBATE POLÍTICO}

Como es apreciable a estas alturas, los dos modelos de análisis fenomenológico que el joven Heidegger pone en marcha están marcados por una determinada concepción previa acerca del carácter de la existencia humana y de la historicidad. El método analizado en las páginas anteriores contiene tesis implícitas que están lejos de poder considerarse neutras y desprejuiciadas. Al contrario, se trata de un instrumentario analítico pensado a partir de una serie de determinaciones sobre la vida que Heidegger nunca pone en cuestión y que, por lo que acabamos de ver, contienen elementos problemáticos en términos políticos.

Sobre la base que nos ofrecen los análisis precedentes, retomemos ahora para finalizar la pregunta directriz sobre el gesto político implicado en las diversas filosofías y sus métodos. Considerando lo que se ha ido transparentando al explicitar la concepción heideggeriana de la historicidad «originaria», bien podemos calificar su postura como idealista, elitista, individualista y heroica. La califico de idealista y elitista porque considera que son los elementos espirituales -las ideas y compresiones sobre el ser humano que unos pocos seres humanos ponen en marcha-lo que operaría transformaciones sustanciales que acabarían vertiéndose, y pervirtiéndose, en la esfera pública. Se trata de una postura que

18 Este menosprecio de lo público y lo político como lugar de generación de lo histórico se aprecia claramente en el modo como Heidegger responde a quienes pretenden reformar la universidad después de la I Guerra Mundial (cf. las «Consideraciones previas» de GA 56/57). 
sólo considera históricamente relevante las interpretaciones que el ser humano hace de sí, interpretaciones que además responderían a motivos ahistóricos y formales como la inquietud por la existencia, la finitud, etc. Aparte, serían sólo unos pocos los que ofrecerían esos elementos interpretativos que acabarían dando lugar a los cambios históricos, por lo que el resto de la humanidad se consideraría en el fondo pasivo y receptivo. Además, se trataría de una posición individualista y heroica porque concede máxima importancia histórica a las estructuras en las que cada Dasein se individualiza, y porque considera el ejercicio filosófico todo como un contramovimiento que debe luchar siempre, una y otra vez, contra las poderosas tendencias cadentes de la vida, expresadas máximamente en las estructuras comunes y públicas de la existencia.

$\mathrm{Al}$ afirmar que las verdaderas revoluciones y los cambios históricos tienen lugar fundamentalmente en el ámbito de la generación y el seguimiento de ideas, entendidas como posibilidades de vida que exigen un cumplimiento y una realización personal, Heidegger estaría rechazando la importancia en los procesos históricos de los elementos materiales, económicos y socio-políticos, así como también de los movimientos sociales. Lejos de ello, otorgaría a la elección de posibilidades en primera persona una primacía originaria, esto es, consideraría como lugar de generación de las realidades históricas al Dasein individual y sus modos de enfrentar el problema de la existencia. Frente a ello conviene presentar de manera muy breve, y como ejemplo que permite un contraste, una posición como la de Marcuse o Adorno, quienes ya en sus primeros escritos criticaron el formalismo de la posición heideggeriana ${ }^{19}$. Éstos, a la inversa que Heidegger, parten de una secundariedad del individuo por respecto a la configuración social ya presente y previa, configuración ésta que además es debida ante todo a procesos y estructuras de corte material, a las condiciones de producción y división del trabajo, mucho más decisivamente que a instancias discursivas o espirituales en general. La actividad filosófica, para centrarnos en el punto que nos interesa, sería concebida como respuesta, y además respuesta crítica, a un estado del mundo que no depende primariamente de la filosofía ni se genera a partir de ella. La vida pública no se considera un sucedáneo impropio de la vida del espíritu, una maraña de posibilidades de vida ya niveladas que en algún momento fueron auténticas posibilidades encarnadas y que esperan ahora ser repetidas, esto es, apropiadas y vivificadas. Lejos de ello, es la vida del espíritu la que se entiende ante todo por respecto a dicha vida pública, que es lo propiamente histórico. La labor del intelectual, por ende, consistirá en interpretar una realidad siempre cambiante y en la que las formas de dominación, explotación y privación de libertad adoptan semblantes nuevos a cada paso. La fragilidad y precariedad del discurso filosófico — su carácter esencialmente negativo - no se basaría en una supuesta estructura ontológica formal ni en tendencia atemporal alguna (como la tendencia al aseguramiento y la huida, que Heidegger considera humanamente estructurales), sino en la

19 Cf. Marcuse (1928) y Adorno (1997). 
constante mutación material del mundo y en la necesidad del discurso de hacer frente y responder a la realidad efectiva y evitar clausurarse en sus propias categorías. La labor del intelectual no pasa por dar la espalda al mundo o interpretar los acontecimientos a la luz de un esquema previo sacado de la propia filosofía, sino que consistiría en intentar entender el mundo en el que vive (las formas de relación social) mediante un ejercicio crítico que debe necesariamente revisar una y otra vez sus elementos conceptuales y metódicos.

Como puede apreciarse, estas dos formas de entender la filosofía parten en última instancia de dos concepciones opuestas del sentido del trabajo filosófico y de su relación con el mundo: un idealismo elitista en el caso de Heidegger y un materialismo crítico en el de Adorno y Marcuse. Considero de interés para el debate actual tener en cuenta que la posición de Heidegger manifiesta desde un principio estos rasgos que ahora tan sólo esbozamos. En ellos, así como también en la confrontación de su postura con la de pensadores que parten de consideraciones diametralmente opuestas, encontramos claves para interpretar las posturas políticas implicadas en el pensamiento de Heidegger, posturas que ahora suscitan de nuevo una necesaria discusión.

\section{OBRAS CITADAS:}

Adorno, Th. W. (1997). Gesammelte Schriften in zwanzig Bänden, Bd. 1. Frankfurt a. M.: Suhrkamp.

Beaulieu, A. (dir.) (2008). Abécédaire de Martin Heidegger. Paris: Vrin/ Les Éditions Sils Maria.

Bambach, Ch. R. (1995). Heidegger, Dilthey and the crisis of historicism. Ithaca/London: Cornell University Press.

Barash, J. A. (2003). «Existence and History: Heidegger's Radical Turning Point between 1918 and 1923», en: Heidegger and the Problem of Historical Meaning, New York: Fordham University Press, pp. 98-131.

Cohen-Halimi y Cohen (2015). Le Cas Trawny, à propos des «cahiers noirs» de Heidegger. Paris: Sens \& Tonka.

De Lara, F. (2008). Phänomenologie der Möglichkeit. Grundzüge der Philosophie Heideggers 1919-1923. Freiburg: Alber.

De Lara, F. (2014). «¿Ciencia originaria o ciencia del origen? Una discusión de la filosofía de Heidegger en sus cursos de 1919 a 1921 », Revista de Humanidades (Universidad Andrés Bello), 30, 2014, pp. 55-75.

Dilthey, W. (2006). Gesammelte Schriften. Band 8.: Weltanschauungslehre. Abhandlungen zur Philosophie der Philosophie. Göttingen: Vandenhoeck \& Ruprecht.

Gander H.-H. (2001). Selbstverständnis und Lebenswelt. Frankfurt am Main: Klostermann.

Gander, H. y Striet, M. (eds.) (2016). Heideggers Weg in die Moderne. Eine Verortung der «Schwarzen Hefte».

Greisch, J. (2000). L'Arbre de vie et l'Arbre du savoir. Les racines phénomenologiques de l'herméneutique heideggerienne (1919-1923). Paris: Les éditions du cerf.

Heidegger, M. (GA 9). «Anmerkungen zu Karl Jaspers Psychologie der Weltanschauungen (1919/1921)», en Wegmarken. Frankfurt a. M., V. Klostermann, 1996², págs. 3-44. Hay 
traducción castellana en Hitos, traducción de Helena Cortés y Arturo Leyte. Madrid: Alianza Editorial, 2000, pp. 15-47.

Heidegger, M. (GA 56/57). Zur Bestimmung der Philosophie. Frankfurt a. M., Klostermann, 1999². Hay traducción castellana de la primera edición: La idea de la filosofía y el problema de la visión del mundo, traducción de Jesús Adrián. Barcelona, Herder, 2005.

Heidegger, M. (GA 58). Grundprobleme der Phänomenologie (1919/1920). Frankfurt a. M., Klostermann, 1993. Hay traducción castellana: Los problemas fundamentales de la fenomenología (1919/1920). Traducción de Francisco de Lara. Madrid: Alianza, 2014.

Heidegger, M. (GA 59). Phänomenologie der Anschauung und des Ausdrucks. Theorie der philosophischen Begriffsbildung. Frankfurt a. M., Klostermann, 1993.

Heidegger, M. (GA 60). Phänomenologie des religiösen Lebens. Frankfurt a. M., Klostermann, 1995. Hay traducción castellana: Introducción a la fenomenología de la religión, trad. de J. Uscatescu. Madrid: Siruela, 2005.

Heidegger, M. (GA 62). Phänomenologische Interpretationen ausgewählten Abhandlungen des Aristoteles zur Ontologie und Logik. Frankfurt a. M., Klostermann, 2005. Hay traducción castellana: Interpretaciones fenomenológicas sobre Aristóteles. Indicación de la situación hermenéutica [Informe Natorp], traducción de J. Adrián. Madrid, Trotta, 2002.

Heidegger, M. (GA 63). Ontologie. Hermeneutik der Faktizität. Frankfurt a. M., Klostermann, 1995². Hay traducción castellana: Ontología. Hermenéutica de la facticidad, traducción de J. Aspiunza, Madrid, Alianza, 1999.

Heinz, M. y Kellerer, S. (eds.) (2016). Martin Heideggers »Schwarze Hefte«: Eine philosophisch-politische Debatte. Frankfurt a. M.: Suhrkamp.

Homolka, H. y Heidegger, A. (eds.) (2016). Heidegger und der Antisemitismus: Positionen im Widerstreit. Freiburg: Herder.

Kim, J.-Ch. (2001). Leben und Dasein. Die Bedeutung Wilhelm Diltheys für den Denkweg Martin Heideggers. Würzburg: Königshausen \& Neumann.

Kisiel, Th. (1997). «Die formale Anzeige. Die methodische Geheimwaffe des frühen Heideggers. Heidegger als Lehrer: Begriffsskizzen an der Wandtafel», en Happel, M. (ed.): Heidegger neu gelesen. Würzburg: Königshausen \& Neumann, pp. 22-40.

Lazzari, R. (2002). Ontologia della fatticità. Prospettive sul giovane Heidegger (Husserl, Dilthey, Natorp, Lask). Milano: Franco Angeli.

Le Moli, A. (2005). «Ontologia e storia nel giovane Heidegger. Note sul confronto con Dilthey (1919-25)», Fieri. Annali del Dipartimento di Filosofia, Storia e Critica dei Saperi, 3, pp. 43-61.

Lepadatu, G. V. (2009). Early Heidegger's Transition from Life to Being. University of Kentucky Doctoral Dissertations, Paper 725, (http://uknowledge.uky.edu/gradschool_ diss/725)

Marcuse, H. (1928). «Beiträge zu einer Phänomenologie des historischen Materialismus», Philosophische Hefte, 1, pp. 45-68.

Martínez Matías, P (2005). «La dinámica de la facticidad», Revista de Filosofía, 30 (2), pp. 89-118.

Mehring, R. (2016). Heideggers "große Politik»: Die semantische Revolution der Gesamtausgabe. Tübingen: Mohr-Siebeck.

Mehring, R. (2018). Martin Heidegger und die «konservative Revolution». Freiburg/ München: Karl Alber. 
Noll, A. (2015). Der rechte Werkmeister: Martin Heidegger nach den »Schwarzen Heften«. Köln: Papyrossa Verlag

Radinković, Ž. (2012). «Phänomenologisch-kritische Destruktion des Aprioriproblems beim frühen Heidegger», Filozofija i društvo, XXIII (4), pp. 251-268.

Rodríguez, R. (1997). La transformación hermenéutica de la fenomenología. Madrid: Tecnos.

Schalow, F. y Denker, A. (2010). Historical Dictionary of Heidegger's Philosophy. Lanham/ Toronto/Plymouth: The Scarecrow Press.

Schmidt, I. (2005). Vom Leben zum Sein. Der frühe Martin Heidegger und die Lebensphilosophie. Würzburg: Königshausen \& Neumann.

Spranger, E. (1921). Lebensformen. Geisteswissenschaftliche Psychologie und Ethik der Persönlichkeit. Halle: Niemeyer.

Volpi, Franco (1988). «L'approccio fenomenologico alla storia della filosofia nel primo Heidegger», Aut-Aut, 223-224, 1988, pp. 203-230.

Pontificia Universidad Católica de Chile

Francisco de LaRa

fdelara@uc.cl

[Artículo aprobado para publicación en diciembre de 2015] 